\title{
Research Paper: \\ The Protective Effects of Nicotine and Bucladesine on Impaired Avoidance Memory Caused by Sodium Arsenate Toxicity in Mice
}

\author{
Sheyda Najafi ${ }^{1}$ (D), Mahmoud Hashemzaei² (D, Maryam Sadeghi ${ }^{3}$ (D), Sajedeh Seyed Mousavi ${ }^{3}$ (D), Ali Bazi ${ }^{4}$ (D), Sahar Fanoudi ${ }^{5}$ (D), Maryam

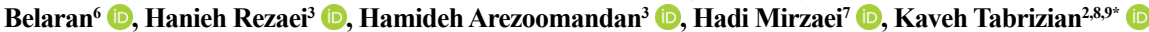

1. Department of Pharmaceutical Care, Faculty of Pharmacy, Tehran University of Medical Sciences, Tehran, Iran.

2. Department of Pharmacology and Toxicology, Faculty of Pharmacy, Zabol University of Medical Sciences, Zabol, Iran.

3. Students Research Committee, Faculty of Pharmacy, Zabol University of Medical Sciences, Zabol, Iran.

4. Department of Hematology, Faculty of Allied Health Sciences, Zabol University of Medical Sciences, Zabol, Iran.

5. Department of Pharmacology, Faculty of Medicine, Mashhad University of Medical Sciences, Mashhad, Iran.

6. Department of Physiology, Faculty of Medicine, Zabol University of Medical Sciences, Zabol, Iran.

7. Department of Biotechnology, Faculty of Medicine, Zabol University of Medical Sciences, Zabol, Iran.

8. Zabol Medicinal Plants Research Center, Zabol University of Medical Sciences, Zabol, Iran.

9. Toxicology and Addiction Research Center, Zabol University of Medical Sciences, Zabol, Iran.

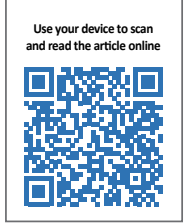

How to cite this paper Najafi S, Hashemzaei M, Sadeghi M, Seyed Mousavi M, Bazi A, Fanoudi S, Belaran M, Rezaei H, Arezoomandan H, Mirzaei H, Tabrizian K. The Protective Effects of Nicotine and Bucladesine on Impaired Avoidance Memory Caused by Sodium Arsenate Toxicity in Mice. Iranian Journal of Toxicology. 2021; 15(2):99-108. http://dx.doi.org/10.32598/ ijt.15.2.772.1.

\section{(i) (5)}

Article info:

Received: 16 Nov 2020

Accepted: 28 Feb 2021

Online Published: 01 Apr 2021

Corresponding author:

Kaveh Tabrizian, PhD.

Address: Department of Pharmacology and Toxicology, Faculty of Pharmacy, Zabol University of Medical Sciences,

Zabol, Iran.

E-mail: k_tabrizian2005@yahoo.com

\section{ABSTRACT}

Background: The toxic effect of sodium arsenate on nervous system has been shown; but the protective effects of several compounds against sodium arsenate are not clear. This study aimed to investigate the protective effects of nicotine and bucladesine, two positive modulators of neuronal function, on sodium arsenate toxicity against avoidance memory impairment.

Methods: Male mice $(\mathrm{N}=154)$ were assigned to 22 groups (12 experimental and 10 control) of seven animals each and were treated as follows: sodium arsenate $(2.5,5$, or $10 \mathrm{mg} / \mathrm{kg})$ for 28 days, nicotine $(1 \mathrm{mg} / \mathrm{kg})$ for either 1,2 , or 4 days, bucladesine $(600 \mathrm{nM} /$ mouse $)$ for either 1,2 , or 4 days, and nicotine $(1 \mathrm{mg} / \mathrm{kg})+$ bucladesine $(600 \mathrm{nM} /$ mouse $)+$ sodium arsenate $(2.5 \mathrm{mg} / \mathrm{kg})$. The last group was treated with $2.5 \mathrm{mg} / \mathrm{kg}$ sodium arsenate first, and then received the combination of nicotine and bucladesine for 1, 2, or 4-days. The corresponding control groups did not receive any drug but either saline, deionized water, or combination of deionized water and DMSO, but went through the same procedure as other animals. All mice were trained $24 \mathrm{~h}$ in the step-through passive avoidance task. The avoidance memory retention was assessed at 24, 48, 96, and $168 \mathrm{~h}$ after the training period by measuring the time they stayed in a dark chamber.

Results: All sodium arsenate doses significantly reduced the time stayed in the dark chamber regardless of the treatment duration $(24,48,96 \& 168 \mathrm{~h})$ after training. Both nicotine and bucladesine, whether used singly or combined for 1,2 , and 4 days significantly enhanced the time latency compared to the controls at all of the experimental timepoints following the training.

Conclusion: Nicotine and bucladesine showed synergistic effects and reversed the sodium arsenate-induced avoidance memory deficits in mice.

Keywords: Sodium arsenate, Nicotine, Bucladesine, Avoidance memory deficit, Memory 


\section{Introduction}

earning and memory are two primordial functions of the Central Nervous System (CNS). Memory is a mechanism for encoding, storage, and retrieval of information [1], while learning is responsible for the acquisition of information from the surrounding environments [2]. The integrity of learning and memory is highly dependent on the function of synapses and signaling pathways in the CNS [3]. Several chemical mediators, such as acetylcholine, glutamate, and norepinephrine have been implicated in promoting neuronal activities [4-6]. The cholinergic system plays a major role in regulating neuronal interactions, learning integrity, and memory functions $[7,8]$. Moreover, cholinergic neurons in the hippocampus are highly essential for cognitive performance [9]. Acetylcholine, as the neurotransmitter of the cholinergic system, triggers numerous post-synaptic events. Choline Acetyltransferase (ChAT) that mediates the synthesis of acetylcholine, and Vesicular Acetylcholine (VAChT) that transports acetylcholine to synaptic vesicles, are the two key markers of the cholinergic system [10]. Also, it has been demonstrated that Protein Kinase A (PKA) promotes the expression of CAT and VAChT genes [11, 12]. Protein kinases are also important in the maintenance of neuronal synaptic functions [13].

As mentioned earlier, PKA is a cAMP-dependent kinase modulating synaptic function and gene expression [14]. It has been shown that the impaired PKA function leads to long-term memory impairment in mice [15]. Conversely, the activation of PKA triggers Mitogen Activated Protein Kinase (MAPK) signaling pathway that regulates the protein phosphorylation and genes expression responsible for the growth and development of new synapses in the CNS [16]. Bucladesine, with multiple functions a phosphodiesterase inhibitor, cAMP agonist and PKA activator, enters the neurons' plasma membrane and is converted to cAMP in the cytoplasm [17]. Also, it regulates the levels of ChAT and VAChT proteins by the Extracellularly Regulated Kinase (ERK) pathway [18]. Bucladasine enhances memory through activating a cAMP/PKA signaling pathway via interaction with such neurotransmitters as dopamine and glutamine [19]. Nicotine influences a wide variety of physiologic activities, such as learning, memory and anxiety by stimulating various neurotransmitters in the CNS [20]. Nicotinic receptors are activated by acetylcholine in the cholinergic system. It has been reported that nicotine dose-dependently affects passive avoidance memory in mice [21] and memory retention in humans [22].
Arsenic (sodium arsenate) is a well-known toxic agent, causing acute and chronic cellular damages. Studies have shown that even low doses of arsenic can affect neurological functions [23, 24]. Also, some studies have reported the effects of arsenic on the central cholinergic system $[25,26]$. It has been shown that arsenic inhibits the synthesis and uptake of acetylcholine in the rat's brain [27]. Also, arsenic negatively affects the learning and memory functions, and neurogenesis through modulating the signaling pathways, involving acetylcholine, glutamate and other monoamines [24, 28-30]. However, the protective roles of nicotine and bucladesine against sodium arsenate-induced impairments are not clear in terms of the retention of avoidance memory. For this reason, we investigated the protective effects of these compounds on passive avoidance memory dysfunction induced by sodium arsenate in mice.

\section{Materials and Methods}

Animal groups: Male mice ( $\mathrm{N}=154)$ weighing 30 $35 \mathrm{~g}$ each were purchased from the Faculty of Pharmacy, Zabol University of Medical Sciences. They were divided into 22 groups of seven each, housed at $25 \pm 2^{\circ} \mathrm{C}, 12$-h light/dark cycles, and with free access to food and water.

Materials: The chemicals used in this study consisted of sodium arsenate ( $\mathrm{Na} 2 \mathrm{HAsO} 4.7 \mathrm{H} 2 \mathrm{O}$; Matheson Coleman \& Bell), Nicotine (Sigma-Aldrich), and Bucladesine (dibutyryl cAMP; a phosphodiesterase inhibitor) were purchased from Sigma Aldrich (St. Louis, MO, USA). The solvents were deionized water, sodium chloride $0.9 \%$, and Dimethyl Sulfoxide (DMSO).

Step-through avoidance learning task: Passive avoidance step-through equipment (Ugo Basile Company, Italy) was used to train the animals. The animals were placed in a light chamber, the gate opened after $10 \mathrm{sec}-$ onds, and the time that the animals waited before going into the dark chamber was recorded as the latency time (300 sec. was set as the cut-off point). Electric shocks at the intensity of $0.2 \mathrm{~mA}$ for $2 \mathrm{sec}$. were delivered to the grid floor of the dark compartment. All training and testing trials were carried out on the same day and time for each animal. No electric shock was given to animals during the retention test.

Experiments: Table 1 illustrates the control and experimental groups, materials' doses, administration routes, and treatment durations. Overall, mice were divided into a total of 22 groups ( $\mathrm{N}=7$ per group) including 12 experimental groups (treated with As, Nic, Bucla, \& combined 
$\mathrm{As}+\mathrm{Nic}+\mathrm{Bucla}$ ) and 10 control groups (one for As, and three for each of the other experimental groups).

Sodium arsenate treatment: Sodium arsenate was dissolved in deionized water and administrated to the assigned groups at a dose of $2.5,5$, or $10 \mathrm{mg} / \mathrm{kg}$. Three groups of mice $(\mathrm{N}=7$, each) orally received $0.5 \mathrm{ml} \mathrm{so-}$ dium arsenate at the above-mentioned doses on a daily basis for 4 weeks. On the $28^{\text {th }}$ day, 30-60 minutes after the last gavage, the animals were trained in the passive avoidance step-through equipment. A 2-sec. shock was given to the floor grid at $0.2 \mathrm{~mA}$ when each mouse was in the light chamber. The latency time for leaving the light chamber and entering the dark chamber was recorded, and the memory acquisition was investigated. Avoidance memory retention was assessed at $24,48,96$, and $168 \mathrm{~h}$ after the training session. During these time periods, no electric shock was used during the passage of animals from the light to the dark chamber. The animals in the control group received $0.5 \mathrm{ml}$ deionized water, otherwise they went through the same procedure as did other mice.

Nicotine treatment: Nicotine at a dose of $1 \mathrm{mg} / \mathrm{kg}$ in normal saline $(0.9 \%)$ was injected intraperitoneally (IP) for either a 1, 2, or 4-day period. Normal saline was injected to the animals in the corresponding control groups for either 1, 2, or 4 days. Following the last treatment, the animals were trained 30-60 minutes after the injection, and then the memory retention test was performed at 24 , 48,96 , and $168 \mathrm{~h}$ post the training session.

Bucladesine treatment: Bucladesine $(600 \mathrm{nM})$ was dissolved in a mixture of DMSO and deionized water at a ratio of 1:9, and injected Intraperitoneally (IP) for either 1, 2, or 4 days. The corresponding controls received $0.3 \mathrm{ml}$ of the DMSO and deionized water (1:9) mixture for either 1, 2, or 4 days. Following the last Bucladesine treatment, the animals were trained for 30-60 minutes and the memory retention test was conducted at 24,48 , 96 , or $168 \mathrm{~h}$ post training.

Combined nicotine $\&$ bucladesine plus sodium arsenate treatment: The animals were treated with arsenate sodium $(2.5 \mathrm{mg} / \mathrm{kg})$ for 4 weeks. Then, they received (IP) a combination of nicotine $(1 \mathrm{mg} / \mathrm{kg})$ and bucladesine sodium $(600 \mathrm{nM})$ for either 1 day (the $\left.28^{\text {th }}\right), 2$ days (the $27^{\text {th }}$ and $28^{\text {th }}$ ), or 4 days (days 25 through 28). Nicotine was first injected followed by bucladesine administration after 15 minutes. On day 28, the sodium arsenate was administered 15 minutes after the bucladesine injection. On this day, the animals were also trained with the stepthrough equipment, and the memory retention test was conducted at $24,48,96$, or $168 \mathrm{~h}$ after the training.
Statistical analyses: GraphPad Prism 5 was used for the statistical analyses. Unpaired t-test, one-way Analysis of Variance (ANOVA) followed by Newman-Keuls post hoc test was used to statistically compare the data. The minimum statistical significance level was set at $\mathrm{P}<0.05$.

\section{Results}

Effects of sodium arsenate on avoidance memory retention: All the sodium arsenate doses reduced the avoidance memory retention as evidenced by significant reductions in the time spent in the dark at 24, 48, 96, and $168 \mathrm{~h}$ after the training as compared to the control group $(\mathrm{P}<0.001$; Table 2).

Effects of nicotine on avoidance memory retention: Compared to the control group, the one-day IP administration of nicotine significantly improved avoidance memory retention with a significant increase in the time spent in the dark after $48 \mathrm{~h}$ of receiving the electric shock $(\mathrm{P}<0.05)$. The 2-day nicotine administration enhanced the avoidance memory following 48 and $96 \mathrm{~h}$ of the electric shock event (Table 3 ). The 4-day nicotine injection significantly improved memory retention at 48 $\mathrm{h}(\mathrm{P}<0.05), 96 \mathrm{~h}(\mathrm{P}<0.001)$, and $168 \mathrm{~h}(\mathrm{P}<0.001)$ following the electric shocks (Table 3 ).

Effects of bucladesine on avoidance memory retention: Compared to the control group, an insignificant increment was observed in the latency time of the animals that received a 1-day bucladesine $(600 \mathrm{nM})$. However, the 2-day injection of this drug significantly increased the latency time to leave the light chamber after $48 \mathrm{~h}$ $(\mathrm{P}<0.01), 96 \mathrm{~h}(\mathrm{P}<0.05)$, and $168 \mathrm{~h}(\mathrm{P}<0.05)$ of the electric shock. After a 4-day injection of bucladesine (600 $\mathrm{nM}$ ), the latency time was significantly increased at all 48,96 , and $168 \mathrm{~h}$ after the electric shock $(\mathrm{P}<0.01)$ compared to the control group (Table 4).

Protection effect of nicotine and bucladesine on sodium arsenate induced deficit of avoidance memory retention: The data indicated that that sodium arsenate at $2.5 \mathrm{mg} / \mathrm{kg}$ significantly attenuated the avoidance memory retention at $24,48,96$, and $168 \mathrm{~h}$ after the training $(\mathrm{P}<0.001)$. The combined nicotine and bucladesine administration for 1,2 or 4 days significantly increased the latency time at 24 (Figure 1A), 48 (Figure 1B), 96 $\mathrm{h}$ (Figure 1C), and $168 \mathrm{~h}$ (Figure 1D) after the training event compared to the controls. 
Table 1. Administered doses of sodium arsenate, nicotine, and bucladesine in the studied groups ( $\mathrm{N}=7 /$ groups)

\begin{tabular}{|c|c|c|c|}
\hline Groups & Doses and Materials & Admin. Route & Duration (day) \\
\hline Control & $\begin{array}{c}\mathrm{Dw}^{\mathrm{a}} \\
\mathrm{Ns}^{\mathrm{b}} \\
\mathrm{DMSO}+\mathrm{Dw}^{\mathrm{c}} \\
\text { Dw, Ns, and DMSO+Dw }\end{array}$ & $\begin{array}{c}\text { Gavage } \\
\text { IP injection } \\
\text { IP injection } \\
\text { Gavage \& } \\
\text { IP injection }\end{array}$ & $\begin{array}{c}28 \\
1,2 \text {, or } 4 \\
1,2 \text {, or } 4 \\
28 \text { days, and } 1,2 \text {, or } 4\end{array}$ \\
\hline As & $2.5,5$, and $10 \mathrm{mg} / \mathrm{kg}$ & Gavage & 28 \\
\hline Nicotine & $1 \mathrm{mg} / \mathrm{kg}$ & IP injection & 1,2 , or 4 \\
\hline Bucladesine & $600 \mathrm{nM}$ & IP injection & 1,2 , or 4 \\
\hline As+Nic+Bucla & $2.5 \mathrm{mg} / \mathrm{kg}+1 \mathrm{mg} / \mathrm{kg}+600 \mathrm{nM}$ & gavage+IP & $\begin{array}{c}28 \text { for As+1, } 2 \text { or } \\
4 \text { days for Nic+Bucla }\end{array}$ \\
\hline
\end{tabular}

IP: Intraperitoneal; Dw: Deionized Water; Ns: Normal saline; DMSO: Dimethyl Sulfoxide; As: Arsenate sodium; Nic: Nicotine; Bucla: Bucladaseine.

${ }^{a}$ Animals received $0.5 \mathrm{~mL} \mathrm{Dw}$, banimals received $0.3 \mathrm{~mL}$ normal saline for either 1, 2, or 4 days (three groups), canimals received $0.3 \mathrm{~mL}$ of DMSO and deionized water (1:9) mixture for either 1, 2, or 4 days (three groups), danimals received $0.3 \mathrm{~mL}$ deionized water (first 28 days and then $0.5 \mathrm{~mL}$ normal saline and $0.3 \mathrm{~mL}$ of DMSO+deionized water (1:9) mixture for either 1, 2, or 4 days (three groups)

\section{Discussion}

Memory is a complex process, which requires different pre- and post-synaptic events. Hippocampus plays a fundamental role in the avoidance memory consolidation [31]. However, memory is not limited to the processing in the hippocampus, rather it is linked to the neural network distributed throughout the brain [32]. The present study investigated the effects of sodium arsenate, nicotine and bucladesine on the retention of avoidance memory in mice. We demonstrated that sodium arsenate reduced avoidance memory retention when administered

Table 2. The effects of sodium arsenate on the time latency (seconds) in avoidance memory retention in step-through

\begin{tabular}{ccccc}
\hline Treatment Group & $\mathbf{2 4} \mathbf{h}$ & $\mathbf{4 8} \mathbf{h}$ & $\mathbf{9 6} \mathbf{h}$ & $\mathbf{1 6 8} \mathbf{h}$ \\
\hline Control $^{\mathrm{a}}$ & $179.1 \pm 35.60$ & $184.2 \pm 30.69$ & $252.5 \pm 22.41$ & $180.9 \pm 35.91$ \\
\hline $2.5 \mathrm{mg} / \mathrm{kg}$ & $23.03 \pm 6.227^{* * *}$ & $19.64 \pm 5.032^{* * *}$ & $22.26 \pm 9.339^{* * *}$ & $25.10 \pm 11.11^{* * *}$ \\
\hline $5 \mathrm{mg} / \mathrm{kg}$ & $27.58 \pm 8.777^{* * *}$ & $23.54 \pm 5.803^{* * *}$ & $9.320 \pm 2.240^{* * *}$ & $9.717 \pm 2.466^{* * *}$ \\
$10 \mathrm{mg} / \mathrm{kg}$ & $27.60 \pm 2.441^{* * *}$ & $13.77 \pm 2.585^{* * *}$ & $9.483 \pm 2.270^{* * *}$ & $11.40 \pm 1.490^{* * *}$ \\
\hline
\end{tabular}

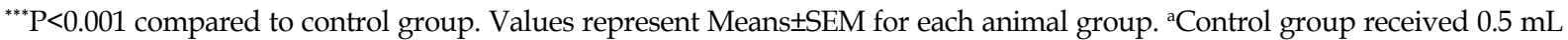
deionized water for 28 days.

Table 3. Time dependent effects of nicotine on the time latency (seconds) in avoidance memory alternations in step-through model

\begin{tabular}{|c|c|c|c|c|c|}
\hline \multicolumn{2}{|c|}{ Treatment Group } & $24 \mathrm{~h}$ & $48 \mathrm{~h}$ & $96 \mathrm{~h}$ & $168 \mathrm{~h}$ \\
\hline \multirow{2}{*}{ 1-day } & Control $^{\mathrm{a}}$ & $45.60 \pm 16.99$ & $28.32 \pm 12.67$ & $15.50 \pm 3.512$ & $18.30 \pm 3.565$ \\
\hline & Nicotine & $190.4 \pm 42.24$ & $205.5 \pm 58.10^{*}$ & $113.7 \pm 49.11$ & $26.53 \pm 6.724$ \\
\hline \multirow{2}{*}{ 2-day } & Control $^{b}$ & $207.6 \pm 41.45$ & $107.8 \pm 52.79$ & $40.72 \pm 6.465$ & $26.44 \pm 13.35$ \\
\hline & Nicotine & $281.7 \pm 13.89$ & $238.4 \pm 44.25^{*}$ & $192.7 \pm 50.30^{*}$ & $66.50 \pm 46.91$ \\
\hline \multirow{2}{*}{ 4-day } & Control $^{\mathrm{c}}$ & $134.2 \pm 49.61$ & $27.77 \pm 13.24$ & $10.80 \pm 1.422$ & $37.48 \pm 29.38$ \\
\hline & Nicotine & $218.2 \pm 47.55$ & $251.7 \pm 48.30^{*}$ & $108.0 \pm 26.00^{* * *}$ & $268.6 \pm 24.34^{* * *}$ \\
\hline
\end{tabular}

${ }^{*} \mathrm{P}<0.05$ and ${ }^{* * *} \mathrm{P}<0.01$ show a considerable difference from control group. Values represent Means $\pm S E M$ for each animal group. $\mathrm{a}, \mathrm{b}, \mathrm{c}$ Control groups received $0.3 \mathrm{~mL}$ normal saline for either 1 (a), 2 (b), or 4 (c) days. 
A

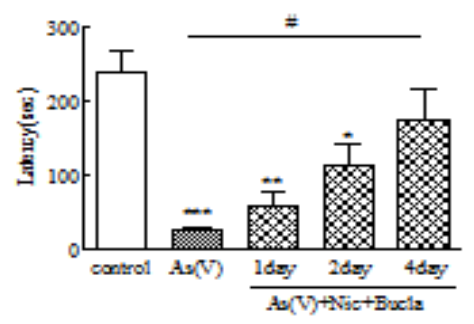

$\mathrm{C}$

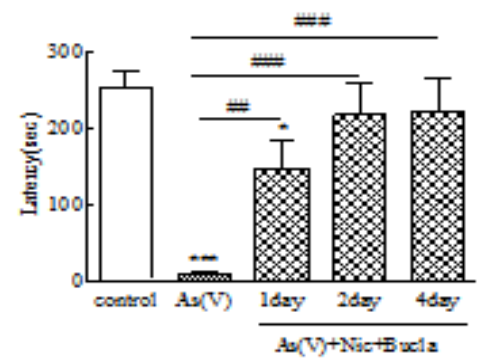

B

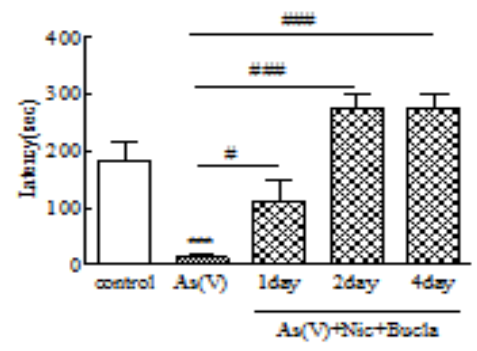

$\mathrm{D}$

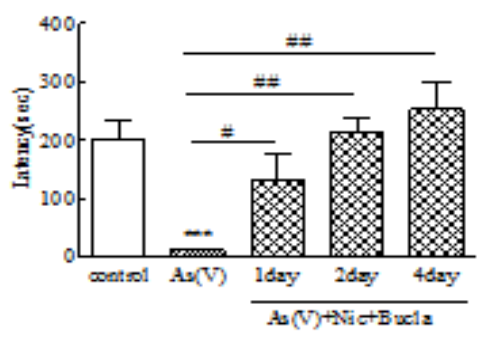

Figure 1. Interaction of nicotine $(1 \mathrm{mg} / \mathrm{kg}$, IP) with bucladesine $(600 \mathrm{nM}, \mathrm{IP})$ on avoidance memory alterations induced by sodium arsenate $(2.5 \mathrm{mg} / \mathrm{kg}$, oral gavage) $24 \mathrm{~h} \mathrm{(a)}, 48 \mathrm{~h}$ (b), $96 \mathrm{~h}$ (c), and $168 \mathrm{~h}$ (d) after training in step-through task

${ }^{*} \mathrm{P}<0.05,{ }^{* *} \mathrm{P}<0.01$ and ${ }^{* * t} \mathrm{P}<0.001$ show significant differences from control group. ${ }^{\#} \mathrm{P}<0.05$, ${ }^{\# \#} \mathrm{P}<0.01$ and ${ }^{\# \# "} \mathrm{P}<0.001$ show significant differences from sodium arsenate -treated group. Values represent Means \pm SEM of 7 animals in each group. Control animals received 0.3 $\mathrm{mL}$ deionized water (first 28 days) and then $0.3 \mathrm{~mL}$ normal saline and $0.3 \mathrm{~mL}$ of DMSO+deionized water (1:9) mixture for either 1, 2, or 4 days (three groups).

for 28 days. In this context, chronic exposure to arsenic has previously been linked to learning and cognitive disturbances [33]. Also, other studies have suggested that long-term exposure to arsenic could affect attention, intelligence, and the ability to comprehend spoken words $[33,34]$. In the current study, the deficit in passive avoidance memory in the arsenic-treated animals showed the deleterious effects of this agent on learning and memory functions, which is consistent with those found by previous studies.

Multiple studies have reported increased levels of glutamine in the motor cortex and hypothalamus following arsenic exposure $[35,36]$. Also, arsenic inhibits the synthesis, release, and uptake of acetylcholine, resulting in memory disturbance [27]. Conversely, the acetylcholine

Table 4. Time dependent effects of bucladesine on the time latency (seconds) in avoidance memory in step-through model

\begin{tabular}{cccccc}
\hline \multicolumn{2}{c}{ Treatment Group } & $\mathbf{2 4 h}$ & $\mathbf{4 8 ~ h}$ & $\mathbf{9 6 ~ h}$ & $\mathbf{1 6 8 ~ \mathbf { ~ h }}$ \\
\hline \multirow{2}{*}{ 1-day } & Control $^{\mathrm{a}}$ & $134.1 \pm 35.84$ & $50.32 \pm 10.81$ & $51.33 \pm 13.80$ & $78.87 \pm 20.51$ \\
& Bucladesine $^{*}$ & $164.6 \pm 38.96$ & $115.3 \pm 39.32$ & $144.0 \pm 40.71$ & $191.9 \pm 37.19$ \\
2-day & Control $^{\mathrm{b}}$ & $195.7 \pm 31.45$ & $62.23 \pm 12.89$ & $40.54 \pm 14.63$ & $18.27 \pm 3.926$ \\
& Bucladesine & $255.6 \pm 32.36$ & $235.3 \pm 29.35^{* *}$ & $243.1 \pm 45.67^{*}$ & $170.3 \pm 33.51^{*}$ \\
4-day & Control & $183.2 \pm 54.73$ & $102.5 \pm 28.33$ & $155.1 \pm 33.86$ & $34.35 \pm 14.11$ \\
& Bucladesine & $275.4 \pm 24.57$ & $263.3 \pm 16.76^{* *}$ & $274.5 \pm 20.88^{* *}$ & $190.8 \pm 25.84^{* *}$ \\
\hline
\end{tabular}

" $\mathrm{P}<0.05$ and " $\mathrm{P}<0.01$ showing a considerable difference compared to the control group.

Values represent Means \pm SEM for each animal group. ${ }^{a, b, c}$ Control groups received $0.3 \mathrm{~mL}$ DMSO and deionized water (1:9) mixture for either 1 (a), 2 (b), or 4 (c) days. 
plays a key role in neuronal function and influences various types of memory and learning processes [37]. Further, cholinergic neurons in the hippocampus have critical roles in cognitive function [38]. Since hippocampus plays a pivotal role in learning and memory modulation [39], learning and memory deficits in arsenic-treated animals might be associated with an impaired cholinergic system. Evidence produced by other studies have suggested that arsenic can disturb anti-oxidants, causing oxidative stress in the brain [40-42]. Oxidative stress has been shown to inhibit or decrease acetylcholine receptors in the hippocampus and frontal cortex in animals treated with arsenic [43].

Modulating the activity of Acetylcholine Esterase (AChE) plays an important role in the synaptic plasticity and is another potential mechanism by which arsenic toxicity impairs neuronal functions [44]. A recent study has shown that both AChE activity and learning and memory functions diminished following exposure of experimental animals to arsenic [45]. Further, arsenic tends to react with the tyrosine residues in $\mathrm{AChE}$, forming a di-ester residue and leading to the inhibition of this enzyme. The inhibition results in the accumulation of acetylcholine in the synaptic clefts and desensitization of cholinergic receptors in the CNS [46, 47].

In the current study, we demonstrated the beneficial time-dependent effects of nicotine on avoidance memory retention. The beneficial effects have previously been demonstrated by several other studies [20, 48, 49]. Nicotinic receptors in the hippocampus regulate such cellular functions as neurotransmission, synaptic plasticity, memory function, and attention [50]. Other studies have asserted that working memory retention could be facilitated by acute or chronic nicotine exposure [51, 52]. It has been noted that nicotine promotes its cognitive effects through the release of multiple neurotransmitters, including acetylcholine, dopamine, and glutamate [53]. Nicotine induces most of its effects via nicotinic acetylcholine receptors in the brain [48]. In a recent study, short-term administration of nicotine increased the extracellular levels of acetylcholine and dopamine, suggesting the existence of an interaction between the two systems [54]. The activation of PKA in response to cAMP is required to facilitate memory formation [55]. It has been reported that nicotinic receptors in the hippocampus could stimulate PKA-I and -II, and MAPK or ERK1/2 signaling pathways, which are involved in a variety of neuronal processes $[18,56]$.

We further demonstrated that bucladesine, either individually or combined with nicotine, could reverse the impaired avoidance memory caused by exposure to arsenic. Bucladesine, as a selective activator of PKA, plays a major role in the regulation of ChAT and VAChT in PC12 cells through the activation of the ERK signaling pathway in $\mathrm{Ca}^{2+}$ and PKA-dependent manners [56]. Evidence shows that cholinergic functions are highly dependent on the expression of VAChT and ChAT in the brain [57]. It has also been recognized that memory induced by fear (e.g. fear of shocks) is regulated by PKA-dependent intracellular cascades [58].

Further, studies have suggested that cAMP plays a significant role in memory formation [59]. In general, the function of PKA is essential for neuronal regulatory mechanisms and such cellular functions as neuronal development, growth and plasticity [60]. Various neurotransmitters and hormones trigger signaling pathways mediated by cAMP as an intracellular secondary messenger [59]. The final target of cAMP in mammals is PKA as a serine-threonine kinase involved in some forms of long-term potentiation and depression [61]. Moreover, the role of cAMP in synaptic plasticity and memory formation has been demonstrated [61]. Lastly, synaptic plasticity, which requires intracellular connections, plays a major role in the regulation of learning and memory functions [62].

\section{Conclusions}

In this study, we used sodium arsenate to induce impairment in avoidance memory retention in mice. It demonstrated the protective effects of nicotine and bucladesine against sodium arsenate-induced toxicity against memory retention. This study also showed that the co-administration of nicotine and bucladesine enhanced avoidance memory retention in mice exposed to sodium-arsenate in a step-through model. The mechanism of action may be through reversing the destructive effects of sodium arsenate partly via the activation of cAMP/PKA pathway in the cholinergic system. As a limitation, in this study we did not assess the molecular pathways which might represent the protective actions of nicotine and bucladesine. It is recommended that the putative molecular pathways involved in the protective effects of nicotine and bucladesine be investigated in future studies, which may help discover new therapeutic agents for the management of memory impairment.

\section{Ethical Considerations}

\section{Compliance with ethical guidelines}

All procedures were conducted according to the current ethical guidelines for the Use of animals in research. 


\section{Funding}

This study was supported by a grant from the office of Deputy for Research, Zabol University of Medical Sciences, Zabol.

\section{Author's contributions}

All authors equally contributed to preparing this article.

\section{Conflict of interest}

The authors declare no conflict of interest with any internal or external entity in conducting this study.

\section{Acknowledgments}

Thanks to the Deputy of Research and technology of Zabol University of Medical Sciences for Financial support.

\section{References}

[1] Milner B, Squire LR, Kandel ER. Cognitive neuroscience and the study of memory. Neuron. 1998; 20(3):445-68. [DOI:10.1016/ S0896-6273(00)80987-3]

[2] Olds J, Disterhoft JF, Segal M, Kornblith CL, Hirsh R. Learning centers of rat brain mapped by measuring latencies of conditioned unit responses. J Neurophysiol. 1972; 35(2):202-19. [DOI:10.1152/jn.1972.35.2.202] [PMID]

[3] Bracciali A, Brunelli M, Cataldo E, Degano P. Stochastic models for the in silico simulation of synaptic processes. BMC Bioinformatics. 2008; 9(suppl 4):S7. [DOI:10.1186/1471-2105-9-S4S7] [PMID] [PMCID]

[4] Fernández-Chacón R, Südhof TC. Genetics of synaptic vesicle function: Toward the complete functional anatomy of an organelle. Annu Rev Physiol. 1999; 61:753-76. [DOI:10.1146/annurev.physiol.61.1.753] [PMID]

[5] Lauri SE, Lamsa K, Pavlov I, Riekki R, Johnson BE, Molnar E et al. Activity blockade increases the number of functional synapses in the hippocampus of newborn rats. Mol Cell Neurosci. 2003; 22(1):107-17. [DOI:10.1016/S1044-7431(02)00012-X]

[6] Schmalbruch H. Fiber composition of the rat sciatic nerve. Anat Rec. 1986; 215(1):71-81. [DOI:10.1002/ar.1092150111] [PMID]

[7] Degroot A, Parent MB. Infusions of physostigmine into the hippocampus or the entorhinal cortex attenuate avoidance retention deficits produced by intra-septal infusions of the GABA agonist muscimol. Brain Res. 2001; 920(1-2):10-8. [DOI:10.1016/ S0006-8993(01)02798-6

[8] Zarrindast MR, Bakhsha A, Rostami P, Shafaghi B. Effects of intrahippocampal injection of GABAergic drugs on memory retention of passive avoidance learning in rats. J Psychopharmacol. 2002; 16(4):313-9. [DOI:10.1177/026988110201600405] [PMID]
[9] Gaykema RP, Luiten PG, Nyakas C, Traber J. Cortical projection patterns of the medial septum-diagonal band complex. J Comp Neurol. 1990; 293(1):103-24. [DOI:10.1002/ cne.902930109] [PMID]

[10] Woolf NJ. Cholinergic systems in mammalian brain and spinal cord. Prog Neurobiol. 1991; 37(6):475-524 [DOI:10.1016/0301-0082(91)90006-M]

[11] Inoue H, Li YP, Wagner JA, Hersh LB. Expression of the choline acetyltransferase gene depends on protein kinase A activity. J Neurochem. 1995; 64(3):985-90. [DOI:10.1046/j.14714159.1995.64030985.x] [PMID]

[12] Weihe E, Eiden LE. Chemical neuroanatomy of the vesicular amine transporters. FASEB J.2000; 14(15):2435-49. [DOI:10.1096/fj.00-0202rev] [PMID]

[13] Lloyd GK, Williams M. Neuronal nicotinic acetylcholine receptors as novel drug targets. J Pharmacol Exp Ther. 2000; 292(2):461-7. https://jpet.aspetjournals.org/content/292/2/461.short

[14] Baulieu E-E, Robel P. Neurosteroids: A new brain function? J Steroid Biochem Mol Biol. 1990; 37(3):395-403 [DOI:10.1016/0960-0760(90)90490-C]

[15] Szapiro G, Izquierdo LA, Alonso M, Barros D, Paratcha G, Ardenghi $\mathrm{P}$, et al. Participation of hippocampal metabotropic glutamate receptors, protein kinase $\mathrm{A}$ and mitogen-activated protein kinases in memory retrieval. Neuroscience. 2000; 99(1):1-5. [DOI:10.1016/S0306-4522(00)00236-0]

[16] Whitehouse PJ, Martino AM, Antuono PG, Lowenstein PR, Coyle JT, Price DL, et al. Nicotinic acetylcholine binding sites in Alzheimer's disease. Brain Res. 1986; 371(1):146-51 [DOI:10.1016/0006-8993(86)90819-X]

[17] Slack J R, Pockett S. Cyclic AMP induces long-term increase in synaptic efficacy in CA1 region of rat hippocampus. Neurosc Lett. 1991; 130(1):69-72. [DOI:10.1016/0304-3940(91)90229-M]

[18] Chetkovich DM, Sweatt JD. nMDA receptor activation increases cyclic AMP in area CA1 of the hippocampus via calcium/ calmodulin stimulation of adenylyl cyclase. J Neurochem. 1993; 61(5):1933-42. [DOI:10.1111/j.1471-4159.1993.tb09836.x] [PMID]

[19] Monsma FJ Jr, Mahan LC, McVittie LD, Gerfen CR, Sibley DR. Molecular cloning and expression of a D1 dopamine receptor linked to adenylyl cyclase activation. Proc Natl Acad Sci US A. 1990; 87(17):6723-7. [DOI:10.1073/pnas.87.17.6723] [PMID] [PMCID]

[20] Janhunen S, Ahtee L. Differential nicotinic regulation of the nigrostriatal and mesolimbic dopaminergic pathways: Implications for drug development. Neurosci Biobehav Rev. 2007; 31(3):287-314. [DOI:10.1016/j.neubiorev.2006.09.008] [PMID]

[21] Zarrindast M-R, Sadegh M, Shafaghi B. Effects of nicotine on memory retrieval in mice. Eur J Pharmacol. 1996; 295(1):1-6. [DOI:10.1016/0014-2999(95)00628-1]

[22] PeekeSC, Peeke HV. Attention, memory, and cigarette smoking. Psychopharmacology. 1984; 84(2):205-16. [DOI:10.1007/ BF00427447] [PMID]

[23] Rahman MM, Hossain KFB, Banik S, Sikder MT, Akter $\mathrm{M}$, Bondad SEC, et al. Selenium and zinc protections against metal-(loids)-induced toxicity and disease manifestations: A review. Ecotoxicol Environ Saf. 2019; 168:146-63. [DOI:10.1016/j. ecoenv.2018.10.054] [PMID] 
[24] Tyler CR, Allan AM. The effects of arsenic exposure on neurological and cognitive dysfunction in human and rodent studies: A review. Curr Environ Health Rep. 2014; 1(2):132-47. [DOI:10.1007/s40572-014-0012-1] [PMID] [PMCID]

[25] Valkonen S, Savolainen H, Järvisalo J. Arsenic distribution and neurochemical effects in peroral sodium arsenite exposure of rats. Bull Environ Contam Toxicol. 1983; 30(3):303-8. [DOI:10.1007/BF01610137] [PMID]

[26] Chandravanshi LP, Gupta R, Shukla RK. Arsenic-Induced neurotoxicity by dysfunctioning cholinergic and dopaminergic system in brain of developing rats. Biol Trace Elem Res. 2019; 189(1):118-33. [DOI:10.1007/s12011-018-1452-5] [PMID]

[27] Jiménez-Capdeville M E, Giordano M. The effects of arsenic exposure on the nervous system. Toxicol Lett. 2003; 145(1):1-18. [DOI:10.1016/S0378-4274(03)00262-5]

[28] Freo U, Pizzolato G, Dam M, Ori C, Battistin L. A short review of cognitive and functional neuroimaging studies of cholinergic drugs: Implications for therapeutic potentials. J Neural Transm. 2002; 109(5-6):857-70. [DOI:10.1007/s007020200070] [PMID]

[29] Jarrard LE, Okaichi H, Steward O, Goldschmidt RB. On the role of hippocampal connections in the performance of place and cue tasks: Comparisons with damage to hippocampus. Behav Neurosci. 1984; 98(6):946-54. [DOI:10.1037/07357044.98.6.946] [PMID]

[30] Mesulam MM, Geula C. Nucleus basalis (Ch4) and cortical cholinergic innervation in the human brain: Observations based on the distribution of acetylcholinesterase and choline acetyltransferase. J Comp Neurol. 1988; 275(2):216-40. [DOI:10.1002/ cne.902750205] [PMID]

[31] Huang WL, Hsiung MH, Dai W, Hu SS. Rottlerin, BDNF, and the impairment of inhibitory avoidance memory. Psychopharmacology. 2021; 238(2):421-39. [DOI:10.1007/s00213-02005690-x] [PMID]

[32] Hall JE, Hall ME. Guyton and Hall textbook of medical physiology- E-Book. Elsevier Health Sciences; 2020. https:/ /www. google.com/books/edition/Guyton_and_Hall_Textbook_ of_Medical_Phys/Po0zyO0BFzwC?hl=en\&gbpv $=0$

[33] Brinkel J, Khan MH, Kraemer A. A systematic review of arsenic exposure and its social and mental health effects with special reference to Bangladesh. Int J Environ Res Public Health. 2009; 6(5):1609-19. [DOI:10.3390/ijerph6051609] [PMID] [PMCID]

[34] Flora SJ, Bhatt K, Mehta A. Arsenic moiety in gallium arsenide is responsible for neuronal apoptosis and behavioral alterations in rats. Toxicol Appl Pharmacol. 2009; 240(2):236-44. [DOI:10.1016/j.taap.2009.05.013] [PMID]

[35] Wang Y, Zhao F, Liao Y, Jin Y, Sun G. Arsenic exposure and glutamate-induced gliotransmitter release from astrocytes. Neural Regen Res. 2012; 7(31):2439-45. https://www.ncbi. nlm.nih.gov/pmc/articles/PMC4200718/

[36] Ramos-Chávez LA, Rendón-López CR, Zepeda A, SilvaAdaya D, Del Razo LM, Gonsebatt ME. Neurological effects of inorganic arsenic exposure: Altered cysteine/glutamate transport, NMDA expression and spatial memory impairment. Front Cell Neurosci. 2015; 9:21. [DOI:10.3389/fncel.2015.00021] [PMID] [PMCID]

[37] Haam J, Yakel JL. Cholinergic modulation of the hippocampal region and memory function. J Neurochem. 2017; 142(suppl 2):111-21. [DOI:10.1111/jnc.14052] [PMID] [PMCID]
[38] Manikandan S, Srikumar R, Jeya Parthasarathy N, Sheela Devi R. Protective effect of Acorus calamus LINN on free radical scavengers and lipid peroxidation in discrete regions of brain against noise stress exposed rat. Biol Pharm Bull. 2005 28(12):2327-30. [DOI:10.1248/bpb.28.2327] [PMID]

[39] Butterweck V, Böckers T, Korte B, Wittkowski W, Winterhoff $\mathrm{H}$. Long-term effects of St. John's wort and hypericin on monoamine levels in rat hypothalamus and hippocampus. Brain Res. 2002; 930(1-2):21-9. [DOI:10.1016/S0006-8993(01)03394-7]

[40] Prakash C, Soni M, Kumar V. Mitochondrial oxidative stress and dysfunction in arsenic neurotoxicity: A review. J Appl Toxicol. 2016; 36(2):179-88. [DOI:10.1002/jat.3256] [PMID]

[41] Chandravanshi LP, Gupta R, Shukla RK. Developmental neurotoxicity of arsenic: Involvement of oxidative stress and mitochondrial functions. Biol Trace Elem Res. 2018; 186(1):18598. [DOI:10.1007/s12011-018-1286-1] [PMID]

[42] Liu Y, Zhao H, Wang Y, Guo M, Mu M, Xing M. Arsenic (III) and/or copper (II) induces oxidative stress in chicken brain and subsequent effects on mitochondrial homeostasis and autophagy. J Inorg Biochem. 2020; 211:111201. [DOI:10.1016/j. jinorgbio.2020.111201] [PMID]

[43] Yadav RS, Sankhwar ML, Shukla RK, Chandra R, Pant AB, Islam $\mathrm{F}$, et al. Attenuation of arsenic neurotoxicity by curcumin in rats. Toxicol Appl Pharmacol. 2009; 240(3):367-76. [DOI:10.1016/j.taap.2009.07.017] [PMID]

[44] Lane RM, Kivipelto M, Greig NH. Acetylcholinesterase and its inhibition in Alzheimer disease. Clin Neuropharmacol. 2004; 27(3):141-9. [DOI:10.1097/00002826-200405000-00011] [PMID]

[45] Feng W, Wu X, Mao G, Zhao T, Wang W, Chen Y, et al. Neurological effects of subchronic exposure to dioctyl phthalate (DOP), lead, and arsenic, individual and mixtures, in immature mice. Environ Sci Pollut Res. 2020; 27(9):9247-60. [DOI:10.1007/ s11356-019-06823-2] [PMID]

[46] Page JD, Wilson IB. Acetylcholinesterase: Inhibition by tetranitromethane and arsenite. Binding of arsenite by tyrosine residues. J Biol Chem. 1985; 260(3):1475-8. [DOI:10.1016/S00219258(18)89616-8]

[47] Zheng Q, Olivier K, Won YK, Pope CN. Comparative cholinergic neurotoxicity of oral chlorpyrifos exposures in preweanling and adult rats. Toxicol Sci. 2000; 55(1):124-32. [DOI:10.1093/toxsci/55.1.124] [PMID]

[48] Poorthuis RB, Goriounova NA, Couey JJ, Mansvelder HD Nicotinic actions on neuronal networks for cognition: General principles and long-term consequences. Biochem Pharmacol. 2009; 78(7):668-76. [DOI:10.1016/j.bcp.2009.04.031] [PMID]

[49] Puma C, Deschaux O, Molimard R, Bizot JC. Nicotine improves memory in an object recognition task in rats. Eur Neuropsychopharmacol. 1999; 9(4):323-7. [DOI:10.1016/S0924977X(99)00002-4]

[50] Levin ED. Complex relationships of nicotinic receptor actions and cognitive functions. Biochem Pharmacol. 2013; 86(8):1145-52. [DOI:10.1016/j.bcp.2013.07.021] [PMID] [PMCID]

[51] Eidi M, Zarrindast MR, Eidi A, Oryan S, Parivar K. Effects of histamine and cholinergic systems on memory retention of passive avoidance learning in rats. Eur J Pharmacol. 2003; 465(12):91-6. [DOI:10.1016/S0014-2999(03)01440-7] 
[52] Zhang L, Spencer TJ, Biederman J, Bhide PG. Attention and working memory deficits in a perinatal nicotine exposure mouse model. PLoS One. 2018; 13(5):e0198064. [DOI:10.1371/ journal.pone.0198064] [PMID] [PMCID]

[53] Picciotto MR. Common aspects of the action of nicotine and other drugs of abuse. Drug Alcohol Depend. 1998; 51(1-2):16572. [DOI:10.1016/S0376-8716(98)00074-X]

[54] Zhou FM, Liang Y, Dani JA. Endogenous nicotinic cholinergic activity regulates dopamine release in the striatum. Nat Neurosci. 2001; 4(12):1224-9. [DOI:10.1038/nn769] [PMID]

[55] Zhu Q, Zhang JW, Zhu HQ, Shen YL, Flexor M, Jia PM, et al Synergic effects of arsenic trioxide and cAMP during acute promyelocytic leukemia cell maturation subtends a novel signaling cross-talk. Blood. 2002; 99(3):1014-22. [DOI:10.1182/blood. V99.3.1014.h80302001014_1014_1022] [PMID]

[56] Dajas-Bailador FA, Mogg AJ, Wonnacott S. Intracellular $\mathrm{Ca} 2+$ signals evoked by stimulation of nicotinic acetylcholine receptors in SH-SY5Y cells: Contribution of voltage-operated $\mathrm{Ca} 2+$ channels and Ca2+ stores. J Neurochem. 2002; 81(3):60614. [DOI:10.1046/j.1471-4159.2002.00846.x] [PMID]

[57] Castell X, Diebler MF, Tomasi M, Bigari C, De Gois S, Berrard S, et al. More than one way to toy with ChAT and VAChT. J Physiol Paris. 2002; 96(1-2):61-72. [DOI:10.1016/S09284257(01)00081-X]

[58] Nijholt IM, Ostroveanu A, Scheper WA, Penke B, Luiten PG, Van der Zee EA, et al. Inhibition of PKA anchoring to A-kinase anchoring proteins impairs consolidation and facilitates extinction of contextual fear memories. Neurobiol Learn Mem. 2008; 90(1):223-9. [DOI:10.1016/j.nlm.2008.03.008] [PMID]

[59] Kandel ER. The molecular biology of memory: cAMP, PKA, CRE, CREB-1, CREB-2, and CPEB. Mol Brain. 2012; 5:14. [DOI:10.1186/1756-6606-5-14] [PMID] [PMCID]

[60] Dagda RK, Das Banerjee T. Role of protein kinase A in regulating mitochondrial function and neuronal development: Implications to neurodegenerative diseases. Rev Neurosci. 2015; 26(3):359-70. [DOI:10.1515/revneuro-2014-0085] [PMID] [PMCID]

[61] Nguyen PV, Woo NH. Regulation of hippocampal synaptic plasticity by cyclic AMP-dependent protein kinases. Prog Neurobiol. 2003; 71(6):401-37. [DOI:10.1016/j.pneurobio.2003.12.003] [PMID]

[62] Bailey CH, Kandel ER, Harris KM. Structural components of synaptic plasticity and memory consolidation. Cold Spring Harb Perspect Biol. 2015; 7(7):a021758. [DOI:10.1101/cshperspect.a021758] [PMID] [PMCID] 
This Page Intentionally Left Blank 